\title{
EDITORIAL
}

\section{A pandemia COVID-19 e as repercussões na atenção à saúde do idoso brasileiro}

Em meados de dezembro de 2019 surgiu uma nova infecção por coronavírus em Wuhan na China. Desde então evidenciou-se que tal infecção se espalhou por diversos países e tornou-se questão de Saúde Pública Internacional ${ }^{1,2}$. Designado por Severe Acute Respiratory Syndrome Coronavirus-2 (Sars-Cov-2) o vírus é o causador da doença Corona Virus Disease-19 (COVID-19) ${ }^{3}$. A situação de transmissibilidade deste vírus têm sido uma preocupação para os serviços de saúde locais em todo o mundo numa tentativa de evitar a sua propagação. Em março de 2020 a Organização Mundial da Saúde, após análises e preocupação com a disseminação e severidades dos casos de infecção do COVID-19 caracterizou o estado atual de pandemia ${ }^{4}$.

Por ser um vírus que apresenta características dinâmicas em cada localidade o mesmo apresenta comportamentos de propagação diferentes ${ }^{5}$. A Sociedade Brasileira de Infectologia aponta três fases epidemiológicas de propagação: casos importados, transmissão local e transmissão comunitária ${ }^{6}$. Em 20 de março de 2020, através da portaria 454 o Ministério da Saúde passa a considerar o Brasil em fase de transmissão comunitária do COVID-19 e estabelece diretrizes e ações para a redução da transmissão e orientação para o manejo dos casos nos serviços de saúde diante do possível impacto nos serviços de saúde ${ }^{3,4}$.

Como até o presente momento não existem medidas terapêuticas farmacológicas específicas que evitam a transmissibilidade do COVID-19, as autoridades sanitárias brasileiras adotaram como medida de contenção para a sua propagação, a adoção de isolamento social ${ }^{3,7}$, haja vista uma preocupação dos impactos que esta nova situação pode causar aos serviços de saúde 6 .

o COVID-19 pode acometer qualquer indivíduo de qualquer faixa etária, no entanto, evidências apontam que a população idosa (60 anos ou mais) e portadores de doenças crônicas possuem risco maior de desenvolver um estado mais grave de manifestação do COVID-194,8. Dados recentes apontam maior probabilidade de óbitos em idosos octogenários (80 anos ou mais) e portadores de comorbidades 9 .

As manifestações clínicas do COVID-19 representam importantes desafios ao sistema de saúde pública brasileira, considerando uma possível insuficiência de leitos, equipamentos e profissionais para atender a um país de extensa proporção territorial como o Brasil ${ }^{10}$.

Assim, a população longeva emerge como público prioritário neste contexto em decorrência de apresentarem particularidades em seu organismo oriundas do processo de senilidade e senescencia ${ }^{9}$. Durante este momento de epidemia, em nível mundial, as estratégias de isolamento e distanciamento social mostram impacto direto a diversas áreas como a economia, educação e até mesmo o próprio ambiente de convívio doméstico das pessoas.

As medidas de prevenção a contaminação comunitária impactaram a todos, porém influenciaram ainda mais a população idosa, no que se refere nas mudanças de relações familiares e nos hábitos regulares de vida e, conflitos intergeracionais. Dado ao número de atingidos e de casos letais acometerem mais pessoas acima de 60 anos, o isolamento social e a impossibilidade de manutenção da autonomia do idoso tem se apresentado como aspecto desafiador na contemporaneidade.

A impossibilidade do convívio presencial e a limitação do contato físico tem sido enfrentada por grande parte da população brasileira pela utilização das novas ferramentas tecnológicas, como o uso do celular e do computador por meio da internet. Tais tecnologias embora potencializadoras neste momento é historicamente pouco utilizada por idosos, devido à baixa escolaridade e acesso a tais recursos.

Há de se destacar também o contexto brasileiro de conformação dos arranjos domiciliares em que os idosos se inserem. A coabitação multigeracional também é um fator preocupante, considerando que grande parte desta população necessita de apoio de familiares para atividades instrumentais de vida diária e questões emocionais.

Outro aspecto relevante envolve a população idosa institucionalizada. Esta população em geral é mais vulnerável do que os idosos inseridos na comunidade, já que o contexto da institucionalização é de alto risco para infecção devido a situação de aglomeração, presença de comorbidades crônicas, elevada dependência para as atividades diárias rotineiras e contato constante com diversos profissionais.

Apesar do senso comum direcionar a crença de que o idoso brasileiro encontra-se aposentado e gozando de uma vida mais "tranquila" com qualidade de vida, na prática muitas das vezes há a necessidade de continuar no mercado de trabalho, uma vez que muitos não conseguem receber o auxílio previdenciário ou necessitam de complementação. No contexto econômico de redução salarial e aumento do desemprego o 
impacto para o idoso que ainda permanece inserido no mercado de trabalho é grande, somando-se ao fato de que em algumas situações ele é o principal provedor familiar.

Considerando o atual cenário epidemiológico brasileiro e a adoção de políticas públicas de enfrentamento da pandemia do COVID-19 muito se tem discutido sobre a disponibilidade de leitos de terapia intensiva e a taxa de ocupação dos mesmos. Embora este seja um indicador importante, ações desenvolvidas pela Atenção Primária à Saúde podem influenciar de modo positivo, a considerar a maior proximidade destes serviços à realidade vivida pelos idosos e o trabalho multissetorial e articulado com outras instâncias e setores de atenção social que garantam proteção aos idosos ${ }^{11}$.

Assim, a pandemia do COVID-19 traz à tona a necessidade de maiores investimentos econômicos, de mão de obra especializada capacitada, infraestrutura dos serviços de saúde e produção científica relacionada a população idosa brasileira. Na contramão vivida pelo não reconhecimento das melhores evidências científicas embasarem a tomada de decisão política em nível federal ${ }^{12}$, materializadas pela resistência de adoção do isolamento social, minimização do real quadro da pandemia e uma instabilidade política, o cenário brasileiro de enfrentamento pandêmico é desafiador, principalmente voltado para a população idosa.

Boa Leitura!

Luan Augusto Alves Garcia

Enfermeiro. Especialista em Vigilância Epidemiológica e Gestão em Saúde Pública. Mestre em Atenção à Saúde. Doutorando do Programa de Pós-Graduação Stricto Sensu em Atenção à Saúde (PPGAS) da Universidade Federal do Triângulo Mineiro (UFTM). Editor Adjunto da REFACS.

\begin{abstract}
Álvaro da Silva Santos
Enfermeiro. Pós-Doutor em Serviço Social. Doutor em Ciências Sociais. Professor Associado do Curso de Graduação em Enfermagem e do PPGAS da UFTM. Editor Científico da REFACS.
\end{abstract}

\title{
REFERÊNCIAS
}

1. Li Q, Guan X, Wu P, Wang X, Zhou L, Tong Y, et al. Early transmission dynamics in Wuhan, China, of Novel CoronavirusInfected Pneumonia. N Engl J Med. [Internet]. 2020 [Citado em 08 abr 2020]; 382(13):1199-207. DOI: 10.1056/NEJMoa2001316

2. Rothan HA, Byrareddy SN. The Epidemiology and pathogenesis of Coronavirus Disease (COVID-19) Outbreak. J Autoimmun [Internet]. 2020 [Citado em 08 abr 2020]; 109:102433. DOI: 10.1016/j.jaut.2020.102433

3. Ministério da Saúde (Br). Secretaria de Vigilância em Saúde. Plano de Contingência Nacional para

Infecção Humana pelo novo Coronavírus COVID-19. Brasília: Ministério da Saúde; 2020.

4. World Health Organization. Coronavirus disease 2019 (COVID-19). Situation Report - 51. Geneva: WHO; março de 2020.

5. Sun P, Lu X, Xu C, Sun W, Pan B. Understanding of COVID-19 based on current evidence. Journal of Medical Virology. [Internet] 2020 [Citado em 08 abr 2020]; 92(6):548-51. DOI: https://doi.org/10.1002/jmv.25722

6. Villela DAM. The value of mitigating epidemic peaks of COVID-19 for more effective public health responses. Rev Soc Bras Med Trop. [Internet]. 2020 [Citado em 19 mai 2020]; 53:e20200135. DOI: 10.1590/0037-8682-0135-2020

7. Belasco AGS, Fonseca CD. Coronavírus 2020. Rev Bras Enferm. [Internet] 2020 [Citado em 20 mai. 2020]; 73(2):e2020n2. DOI: http://dx.doi.org/10.1590/0034-7167-2020730201

8. Hellewell J, Abbott S, Gimma A, Bosse NI, Jarvis CI, Russell TW, et al. Feasibility of controlling COVID-19 outbreaks by isolation of cases and contacts. Lancet Glob Health [Internet]. 2020 [Acesso em 21 abr 2020]; 8(4):488-96. DOI: https://doi.org/10.1016/S2214-109X(20)30074-7

9. Hammerschmidt KSA, Santana RF. Saúde do idoso em tempos de pandemia COVID-19. Cogitare Enferm. [Internet]. 2020 [Citado em 20 mai 2020]; 25:e72849. D0I: dx.doi.org/10.5380/ce.v25i0.72849

10. Albuquerque NLS. Planejamento operacional durante a pandemia de Covid-19: comparação entre recomendações da Organização Mundial da Saúde e o Plano de Contingência Nacional. Cogitare Enferm. [Internet]. 2020 [acesso em 20 mai 2020]; 25. DOI: http://dx.doi.org/10.5380/ce.v25i0.72659

11. Lima KC, Nunes VMA, Rocha NSPD, Rocha PM, Andrade I, Uchoa SAC, et al. A pessoa idosa domiciliada sob distanciamento social: possibilidades de enfrentamento à covid-19. Rev Bras Geriatr Gerontol. [Internet]. 2020 [Citado em 15 abr 2020]; 23(2):e200092. DOI: http://dx.doi.org/10.1590/1981-22562020023.200092

12. The Lancet. COVID-19 in Brazil: “So what?” [Editorial]. Lancet Glob Health. [Internet]. 2020 [Acesso em 21 abr 2020]; 395(10235):1461. DOI: https://doi.org/10.1016/S0140-6736(20)31095-3 